
\title{
$\begin{array}{ll}\text { Research Square } & \text { They should not be considered concluavive used to inform celinical practice, } \\ \text { or referenced by the medias validated information. }\end{array}$
}

\section{Mental health of Covid-19 risk groups during the first Covid-19 lockdown in Germany: a cross-sectional study}

\section{Daniel Deimel ( $\square$ d.deimel@katho-nrw.de)}

German Institute for Addiction and Prevention Research, Catholic University of Applied Sciences of North Rhine-Westphalia

Thorsten Köhler

German Institute for Addiction and Prevention Research, Catholic University of Applied Sciences of North Rhine-Westphalia

Janina Dyba

German Institute for Addiction and Prevention Research, Catholic University of Applied Sciences of North Rhine-Westphalia Niels Graf

German Institute for Addiction and Prevention Research, Catholic University of Applied Sciences of North Rhine-Westphalia Christine Firk

Catholic University of Applied Sciences of North Rhine-Westphalia

\section{Research Article}

Keywords: Covid-19, pandemic, mental health, Covid-19 risk group, Germany

Posted Date: August 17th, 2021

DOI: https://doi.org/10.21203/rs.3.rs-612420/v1

License: (c) (i) This work is licensed under a Creative Commons Attribution 4.0 International License. Read Full License 


\section{Abstract \\ Background}

The ongoing Covid-19 pandemic not only threats physical health, but also affects the mental health of people. Yet, health consequences of the pandemic do not affect all members of society equally. We, therefore, assessed the mental health burden of individuals who are at increased risk of severe illness from Covid-19 compared to individuals who are at low risk of severe illness during the first lockdown in Germany. Furthermore, we investigated variables mediating the effect of being an individual at increased risk of serve illness on depression.

\section{Methods}

Adult German residents $(n=2.369)$ provided responses to a cross-sectional online survey about risk factors for an increased risk of severe illness from Covid-19 and various aspects of mental health during the first Covid-19 lockdown in Germany. Standardized and validated self-report measures (e.g. PHQ-9, GAD-7) were used using Mann-Whitney U-tests as well as regression and mediation analyses.

\section{Results}

The results clearly show that the mental health burden is higher among persons at increased risk of severe illness from Covid-19 compared to persons at low risk of severe illness from Covid-19. Moreover, our findings indicate that individuals at increased risk of severe illness are more worried about their health during the pandemic and may therefore respond with social withdrawal to protect themselves and, consequently, experience higher levels of loneliness, which in turn has an impact on depressive symptoms.

\section{Conclusions}

Individuals at increased risk of severe illness have an increased need for psychosocial support during times of lockdown. Future public health policies should pay special attention to these individuals and support them by targeted offers. More research, however, is needed on possible longterm consequences of social distancing on mental health.

\section{Introduction}

The most recently discovered coronavirus, known as severe acute respiratory syndrome coronavirus 2 (SARS-CoV-2), has spread globally within a few months after its first identification in December 2019. The World Health Organization (WHO) declared the Covid-19 disease caused by the virus as a pandemic on 11 March 2020. In Germany, the first case of Covid-19 was confirmed on 27 January 2020. First infection clusters emerged in the federal states North Rhine-Westphalia and Bavaria throughout February 2020 (BMG, 2021). Subsequently, Covid-19 cases increased rapidly, culminating in about 6,016 new cases on March $16^{\text {th }} 2020$ (RKI, 2021a). As of June 2020, by the end of the so-called "first wave", 183,594 persons had been diagnosed with a SARS-CoV-2 infection in Germany and the number of deaths registered in this group amounted to 8,555 (Johns Hopkins University, 2021). The cumulative rate of officially recognised Covid-19-associated hospitalisations in Germany is $10 \%$ (RKI, $2021 \mathrm{~b}$ ).

Older people above the age of 50-60 and people with underlying medical conditions, such as heart conditions, chronic obstructive pulmonary disease (COPD) or obesity, are at increased risk of severe illness from Covid-19 (Jordan et al. 2020, Gao et al. 2020). On 22 March 2020, the German government imposed a first lockdown to reduce infection rates and thus protect these vulnerable groups and maintain the proper functioning of the health care system. This lockdown included the closing of schools, stores, restaurants, bars, clubs, social venues and prohibited any form of mass gatherings. In addition, citizens were urged to minimized personal social contact and keep a minimum distance of 1.5 metres from one another (Bundesregierung, 2020). This lockdown lasted until 4 May 2020 and associated regulations were gradually eased by 15 June 2020 (see figure 1 ).

These governmental actions aim at a reduction of social contacts. Social distancing however may be associated with a substantial mental health burden based on evidence for an association between social isolation and (mental) health problems (Cacioppo et al. 2011; Matthews et al 2016). This is also supported by recent studies showing that the Covid-19 pandemic and related regulations are associated with increases in anxiety, depression and psychological distress (Bäuerle, 2020, Gualano, 2020, Salari, 2020). The increase in mental health problems may in turn also increase dysfunctional coping and emotion regulation strategies such as substance use (Horigian et al, 2021). Even though these mental health impacts of the Covid-19 pandemic may be more significant for those who are prone to psychological problems (Cullen et al, 2020), previous studies have not taken into account the mental health of individuals at increased risk of severe illness from Covid-19 due to their age or underlying medical 
conditions (Jordan et al, 2020, Gao et al, 2020). Yet, individuals at risk of severe illness from Covid-19 may be more concerned about their own health, which may increase stress levels and thereby mental health problems such as anxiety or depression.

The primary aim of the present study, therefore, is the investigation of the mental health burden of individuals who are at increased risk of severe illness from Covid-19 (high risk group for Covid-19, HRGC) compared to individuals who are at low risk of severe illness (low risk group for Covid-19, LRGC). The central hypothesis is that individuals of the HRGC are more anxious and experience more depressive symptoms due to the pandemic than individuals of the LRGC. Based on associations between anxiety, depression and substance use, we moreover expect that HRCG individuals report enhanced substance use. Furthermore, the impact of own health concerns due to COVID-19, perceived stress due to lockdown measures and loneliness during social distancing as well as trust in governmental actions to fight Covid-19 on depressive symptoms are considered in regression and mediation analyses.

\section{Methods}

\section{Study design and data collection}

Cross-sectional data were collected via an online survey from 1 June 2020 until 17 July 2020. The survey was developed in LimeSurvey (LimeSurvey $\mathrm{GmbH}$, Hamburg). The weblink of the survey was included in an advert that was promoted on the websites and social media platforms of several German social service organisations and associations (German AIDS Service Organisations, German Society for Social Psychiatry, German Federation of Telephone Emergency Services, German Federation for Social Work in the Healthcare System, German Society for Social Work in Addiction Aid).

To be able to participate in the study, participants had to be at least 18 years of age and have sufficient knowledge of the German language. Participants did not get any compensation for participating in the survey. In total, 3,154 people were reached through the online survey. For this study, a subset of participants $(n=2.369)$ has been analysed for the sake of comparing the mental health burden of HRGC and LRGC participants.

\section{Measures included in the survey}

The survey started with comprehensive participant information and consent forms. This introductory part was followed by 132 items on sociodemographics, participants' mental health status, their perceptions of the Covid-19 pandemic and the governmental actions designed to encounter the pandemic. All items on mental health were part of standardized and validated self-report measures. Subscales of the German version of the Patient Health Questionnaire (PHQ-D) (Gräf et al. 2004) were used to assess levels of depression (PHQ-9) (Kromke et al. 2006), anxiety (GAD7) (Löwe et al. 2008) and somatisation (PHQ-15) (Kocalevent 2013). Suicidality was captured by the first item of the German version of the Suicide Behaviours Questionnaire - Revised (SBQ-R) which is acknowledged as a reliable instrument to assess suicidal risk (in its single form or in combination with three other items) (Glaesmer et al. 2018, Osman et al. 2001). This item was complemented by a question on suicidal ideation during the first lockdown in Germany ("How often have you thought about killing yourself during the lockdown?"). Emotional and social loneliness were surveyed by the 11-item De Jong Gierveld Loneliness Scale (de Jong-Gievelt \& van Tilburg 1999), while the level of social support was assessed with the help of the Oslo 3 Social Support Scale (OSSS-3) (Kilpelätina et al. 2018, Kocalevent et al. 2018). Moreover, the use of alcohol, nicotine and a range of illegal substances during the last 12 months as well as changes in substance use during the lockdown were assessed by asking the participants which substances they used in the last 12 months respectively during the first lockdown.

To differentiate between HRGC and LRGC participants, risk factors for an increased risk of severe illness from Covid-19 were assessed by the criteria of the Robert Koch Institute (RKI, 2020) which include smoking, obesity, cardiovascualar diseases, chronic lung diseases, diabetes mellitus, cancer, and a compromised immune system. If at least one of these criteria was met, participants were included in the HRGC group.

\section{Statistical Analysis}

The analyses presented here compare two groups: (i) individuals at increased risk of severe illness from Covid-19 ( $n=1.136$; HRGC group) and (ii) Individuals at low risk of severe illness from Covid-19 ( $n=1.233$; LRGC group). Data analysis was conducted using IBM SPSS Statistics 25.0. Significance level of $p<0.05$ was considered in all analyses.

For group comparisons regarding numerical variables Mann-Whitney U-tests were performed since all tested variables were not normally distributed. Cohen's $d$ is reported as the estimated effect size for statistically significant results. The distribution of categorical variables was assessed by Chisquare tests. Spearmann correlation coefficient ware used to determine correlations between ordinal variables. Additionally, mediation analysis using PROCESS macro (Hayes, 2013) for SPSS 25 (IBM corp., Armonk, USA) was run to explore, whether concerns about the own health and feelings of loneliness mediated depressive symptoms.

Multiple mediator models were performed to estimate indirect effects (Hayes \& Rockwood, 2016). All analyses were based on 5000 bootstrapped samples. An indirect effect was considered significant, if the 95\% bias-corrected confidence interval did not include zero (Hayes, 2013). 


\section{Results}

\section{Sample characteristics}

Of the 3,154 persons who commenced the survey, 2.369 participants completed questions on Covid-19 risk factors (75.11\%). 47 percent ( $n=1,291$ ) of those participants were classified into the HRGC. Data of non-completers were included on a pairwise basis, resulting in a different number of responses per analysis (for details on the sociodemographic characteristics of the HRGC and the LRGC, see Table 1).

Table 1: Sociodemographic characteristics

\begin{tabular}{|c|c|c|c|c|c|}
\hline \multirow[t]{2}{*}{ Variable } & \multicolumn{2}{|c|}{ COVID-19 risk group } & \multicolumn{2}{|c|}{ Non-COVID-19 risk group } & \multirow{2}{*}{$\begin{array}{c}p \text {-value } \\
t \text {-test }\end{array}$} \\
\hline & $N$ & $M(S D)$ & $N$ & $M(S D)$ & \\
\hline Age & 1,136 & $46.1(14.8)$ & 1,233 & 39.4 (14.6) & .460 \\
\hline & $N$ & $\%$ & $N$ & $\%$ & $\mathrm{x}^{2}$ \\
\hline Gender identity & 1,137 & & 1,236 & & $.000^{* * *}$ \\
\hline Female & 706 & 62.1 & 896 & 72.5 & \\
\hline Male & 412 & 36.2 & 323 & 26.1 & \\
\hline Diverse & 19 & 1.7 & 17 & 1.4 & \\
\hline Employment status & 1,291 & & 1.406 & & $.000^{* * *}$ \\
\hline Full-time employed & 483 & 37.4 & 501 & 35.6 & \\
\hline Part-time employed & 298 & 23.1 & 386 & 27.5 & \\
\hline Retired & 196 & 15.2 & 77 & 5.5 & \\
\hline Student & 154 & 11.9 & 325 & 23.1 & \\
\hline Unemployed & 73 & 5.7 & 28 & 2.0 & \\
\hline Other & 87 & 6.7 & 89 & 6.3 & \\
\hline Monthly net income & 1,101 & & 1,188 & & $.000^{* * *}$ \\
\hline$<1.000$ Euros & 248 & 22.5 & 357 & 30.1 & \\
\hline 1.000-2.000 Euros & 382 & 34.7 & 362 & 30.5 & \\
\hline 2.000-3.000 Euros & 289 & 26.2 & 311 & 26.2 & \\
\hline More than 3.000 Euros & 182 & 16.5 & 158 & 13.3 & \\
\hline Education & 1,133 & & 1,237 & & $.037^{*}$ \\
\hline University or university of applied sciences diploma & 557 & 49.2 & 677 & 54.7 & \\
\hline Completed vocational education & 152 & 13.4 & 133 & 10.8 & \\
\hline Completion of secondary school & 417 & 36.8 & 421 & 36.8 & \\
\hline Other/none & 7 & 0.6 & 6 & 0.5 & \\
\hline
\end{tabular}

Note: $* p<.05 ; * * * p<.001$

\section{Mental health measures}

In total, $30.9 \%$ of the participants of both groups reported symptoms of a moderate depression on the PHQ-9 scale (score of 10 or higher). The median PHQ-9 score was significantly higher in the HRGC than in the LRGC group (hier würde ich die Teststatistik ergänzen). 35.6\% of the HRGC participants and 26.6\% of the LRGC participants had a PHQ-9 score of 10 or higher and, therefore, exhibited moderate depressive symptoms. Compared to the LRGC, the median GAD-7 score of the HRGC was also significantly higher. Here, 29.6\% of the HRGC participants and $21.4 \%$ of the LRGC participants showed at least moderate levels of generalized anxiety disorders (GAD-7 score $\geq 10$ ). A similar pattern applies to somatic symptoms. The median PHQ-15 score was again significantly higher in the HRGC than in the LRGC group. 15,6\% of the HRGC participants and 7.6\% of the LRGC participants exhibited at least moderate somatic symptoms (PHQ-15 score $\geq 10$ ). In total, $14.4 \%$ of the participants showed an elevated risk for suicide (SBQ-R Item $1 \geq 3$ ). Again, an elevated risk for suicide was significantly higher in the HRGC than in the LRGC (19.5\% vs. 9.7\%) group . The same results can be found for the median suicidal ideation during the lockdown (see table 2).

Table 2: Mental health 


\begin{tabular}{|c|c|c|c|c|c|c|c|c|c|}
\hline \multirow[t]{2}{*}{ Variable } & \multicolumn{3}{|c|}{ HRGC } & \multicolumn{3}{|c|}{ LRGC } & \multirow{2}{*}{$\begin{array}{c}\text { Test statistic } \\
\text { Mann-Whitney U } \\
\end{array}$} & \multirow{2}{*}{$\begin{array}{c}\text { Significance } \\
p \text {-value }\end{array}$} & \multirow{2}{*}{$\begin{array}{c}\text { Effect size } \\
r \\
\end{array}$} \\
\hline & $N$ & Mdn (IQR) & $\mathbf{M}$ & $N$ & Mdn (IQR) & $\mathbf{M}$ & & & \\
\hline :core & 1,083 & $6.00(9.00)$ & 7.9 & 1,182 & $5.00(7.00)$ & 6.39 & 552002,5 & $.000^{* * *}$ & 0.12 \\
\hline core & 1,078 & $6.00(8.00)$ & 7.18 & 1,189 & $5.00(7.00)$ & 6.04 & 565787,0 & $.000^{* * *}$ & 0.10 \\
\hline \multirow[t]{2}{*}{ score } & 846 & $4.00(6.00)$ & 5.11 & 1,017 & $3.00(4.00)$ & 3.73 & 349393,5 & $.000^{* * * *}$ & 0.16 \\
\hline & $N$ & $\%$ & & $N$ & $\%$ & & $\mathrm{x}^{2}$ & $p$-value & $\mathrm{Phi}$ \\
\hline :core $\geq 10$ & 351 & 35.6 & & 282 & 26.6 & & 19,203 & $.000^{* * *}$ & 0.097 \\
\hline core $\geq 10$ & 319 & 29.6 & & 255 & 21.4 & & 19,838 & $.000^{* * *}$ & 0.094 \\
\hline score $\geq 10$ & 132 & 15.6 & & 77 & 7.6 & & 29,910 & $.000^{* * *}$ & 0.127 \\
\hline \multirow[t]{2}{*}{ ity lifetime SBQ-R Item $1 \geq 3$} & 227 & 19.5 & & 124 & 9.7 & & 47,544 & $.000^{* * *}$ & 0.435 \\
\hline & $N$ & $\mathrm{Mdn}(\mathrm{IQR})$ & $\mathbf{M}$ & $N$ & Mdn (IQR) & M & Mann-Whitney U & $p$-value & $r$ \\
\hline thoughts during lockdown & 535 & $1.0(1.00)$ & 1,76 & 432 & $1.0(1.00)$ & 1,59 & 107184,5 & $.026^{*}$ & 0.125 \\
\hline
\end{tabular}

Note: $* p<.05 ; * * * p<.001$

\section{Substance use during lockdown}

There were no significant differences between the HRGC and the LRGC group for alcohol use during the lockdown. In contrast, the use of nicotine and THC during the lockdown differed significantly between the two groups. $20.1 \%$ of the HRGC reported an increased use of nicotine during the lockdown compared to $6.1 \%$ of the LRGC participants. An increased use of THC during the lockdown was reported by $6.7 \%$ of the HRGC individuals compared to $2.1 \%$ of the LRGC participants (see table 3 ).

Table 3: Descriptive statistics and $\mathrm{X} \square$ results for substance use in the HRGC and LRGC

\begin{tabular}{|l|c|c|c|c|c|c|}
\hline \multicolumn{1}{|c|}{ Variable } & \multicolumn{2}{|c|}{ HRGC } & \multicolumn{2}{c|}{ LRGC } & p-value & Effect size \\
\hline & $N$ & $\%$ & $N$ & $\%$ & $\boldsymbol{X}^{2}$ & Phi \\
\hline Substance use in the last12 months & & & & & & \\
\hline Alcohol & 1,056 & 97.4 & 1,151 & 93.4 & .190 & \\
\hline Nicotine & 618 & 62.5 & 302 & 29.3 & $.000^{* * *}$ & 0.333 \\
\hline THC & 292 & 30.5 & 186 & 17.3 & $.000^{* * *}$ & 0.155 \\
\hline Cocaine & 56 & 5.3 & 23 & 1.9 & $.000^{* * *}$ & 0.093 \\
\hline Amphetamines & 69 & 6.5 & 29 & 2.4 & $.000^{* * *}$ & 0.101 \\
\hline Methamphetamines & 23 & 2.1 & 8 & 0.7 & $.002^{* *}$ & 0.064 \\
\hline Ecstasy & 65 & 6.2 & 33 & 2.7 & $.000^{* * *}$ & 0.084 \\
\hline Alcohol use during lockdown & 1,137 & & 1,259 & & $.046^{*}$ & 0.064 \\
\hline No use & 231 & 20.3 & 226 & 18.0 & & \\
\hline Less than before & 187 & 16.4 & 210 & 16.7 & & \\
\hline No change & 416 & 36.6 & 500 & 39.7 & & \\
\hline Slightly more than before & 228 & 20.1 & 269 & 21.4 & & \\
\hline Signific antly more than before & 75 & 6.6 & 54 & 4.3 & & \\
\hline Nicotine use during lockdown & 1,106 & & 1,177 & & $.000^{* * * *}$ & 0.391 \\
\hline No use & 529 & 47.8 & 988 & 83.9 & & \\
\hline Less than before & 69 & 6.2 & 44 & 3.7 & & \\
\hline No change & 286 & 25.9 & 100 & 8.5 & & \\
\hline Slightly more than before & 160 & 14.5 & 32 & 2.7 & & \\
\hline Signific antly more than before & 62 & 5.6 & 13 & 1.1 & & \\
\hline THC use during lockdown & 1,069 & & 1,185 & & $.000^{* * *}$ & 0.148 \\
\hline No use & 859 & 80.4 & 1064 & 89.8 & & \\
\hline Less than before & 39 & 3.6 & 28 & 2.4 & & \\
\hline No change & 100 & 9.4 & 68 & 5.7 & & \\
\hline Slightly more than before & 50 & 4.7 & 23 & 1.9 & & \\
\hline Signific antly more than before & 21 & 2.0 & 2 & 0.2 & & \\
\hline
\end{tabular}

Note: $* p<.05 ; * * p<.01 ; * * * p<.001$

\section{Loneliness, social support and professional assistance}

Loneliness, however, was significantly higher in the HRGC group compared to the LRGC (7.3\% vs. 3.8\%). The level of perceived social support did not differ significantly between both groups (see table 4).

Feelings of stress associated with social distancing did not differ significantly between both groups. HRGC individuals, however, were significantly more likely to perceive government actions to encounter Covid-19 as legitimate and meaningful than LRGC participants. Generally, HRGC individuals were significantly more concerned about the pandemic than LRGC participants. Here, HRGC individuals were significantly more worried about their own health, the health of their friends, the health system in Germany, their financial situation as well as the German economic and political system than LRGC participants (see table 4). 
Table 4: Dealing with the pandemic

\begin{tabular}{|c|c|c|c|c|c|c|c|c|c|}
\hline \multirow[t]{2}{*}{ Variable } & \multicolumn{3}{|c|}{ HRGC } & \multicolumn{3}{|c|}{ LRGC } & \multirow{2}{*}{$\begin{array}{c}\text { Test statistic } \\
x^{2}\end{array}$} & \multirow{2}{*}{$\begin{array}{c}\text { Significance } \\
p \text {-value }\end{array}$} & \multirow{2}{*}{$\begin{array}{c}\text { Effect size } \\
\mathrm{Phi}\end{array}$} \\
\hline & $N$ & \multicolumn{2}{|l|}{$\%$} & $N$ & \multicolumn{2}{|l|}{$\%$} & & & \\
\hline tem De Jong Gierveld Loneliness Scale) score $\geq 16$ & 77 & \multicolumn{2}{|l|}{7.3} & 45 & \multicolumn{2}{|l|}{3.8} & 13,005 & $.000^{* * *}$ & 0.076 \\
\hline \multirow{2}{*}{ (OSSS-3) score $\geq 12$} & 250 & \multicolumn{2}{|l|}{22.4} & 300 & \multicolumn{2}{|l|}{25.0} & 2,260 & .133 & \\
\hline & $N$ & $\mathrm{Mdn}(\mathrm{IQR})$ & $\mathrm{M}$ & $N$ & Mdn (IQR) & $\mathrm{M}$ & Mann-Whitney-U & $p$-value & $r$ \\
\hline al distancing & 1,289 & $4.00(3.00)$ & 3.51 & 1,408 & $3.00(2.00)$ & 3.44 & 881196,0 & .185 & \\
\hline of social distancing & 1,284 & $5.00(2.00)$ & 4.88 & 1,402 & $5.00(2.00)$ & 4.77 & 840222,0 & $.002^{* *}$ & 0.060 \\
\hline \multicolumn{10}{|l|}{ the pandemic... } \\
\hline own health & 1,282 & $3.00(2.00)$ & 2.94 & 1,398 & $2.00(2.00)$ & 2.3 & 685748,5 & $.000^{* * *}$ & 0.208 \\
\hline the health of friends & 1,271 & $4.00(2.00)$ & 4.08 & 1,402 & $4.00(2.00)$ & 3.96 & 844683,0 & $.018^{*}$ & 0.045 \\
\hline own financial & 1,271 & $2.00(2.00)$ & 2.39 & 1,406 & $2.00(2.00)$ & 2.14 & 827655,5 & $.000^{* * *}$ & 0.067 \\
\hline the German healthcare system & 1,279 & $3.00(2.00)$ & 2.84 & 1,396 & $2.00(3.00)$ & 2.63 & 822044,0 & $.000^{* * * *}$ & 0.070 \\
\hline the German economy & 1,277 & $4.00(2.00)$ & 3.99 & 1,396 & $4.00(2.00)$ & 3.8 & 818631,5 & $.000^{* * *}$ & 0.072 \\
\hline the German political system & 1,274 & $4.00(2.00)$ & 3.96 & 1,383 & $4.00(2.00)$ & 3.79 & 820626,5 & $.002^{* *}$ & 0.060 \\
\hline
\end{tabular}

Note: ${ }^{*} p<.05 ; * * p<.01 ; * * p<.001$

\section{Factors contributing to depressive symptoms during the lockdown}

Bivariate correlations showed a significant positive association between depression, loneliness and the perceived stress level due to social distancing. In contrast, the perceived meaningfulness of government actions to encounter Covid-19 is negatively associated with depression, loneliness, and the perceived stress level due to social distancing (see table 5).

Table 5: Bivariate correlations of loneliness, depression and stress due to social distancing.

\begin{tabular}{|ll|c|c|c|}
\hline & & 1 & 2 & 3 \\
\hline 1 & Depression & 1 & & \\
\hline 2 & Loneliness & $.591^{* *}$ & 1 & \\
\hline 3 & Stress due to social distancing during lockdown & $.406^{* *}$ & $.400^{* *}$ & 1 \\
\hline
\end{tabular}

$* *=p<0.01$

Binary logistic regression was used to identify predictors of depression during the lockdown. Being male $(\mathrm{OR}=1.72$, 95\% CI: 1.30 2.27), younger age $(\mathrm{OR}=0.98,95 \% \mathrm{CI}: 0.97-0.99)$, being a HRGC individual $(\mathrm{OR}=1.47,95 \% \mathrm{CI}: 1.13-1.90)$, loneliness $(\mathrm{OR}=1.31$, 95\% CI: 1.27-1.35), worries about the own health (OR $=1.14,95 \%$ CI: 1.04-1.24), as well as perceived stress due to social distancing $(\mathrm{OR}=1.29,95 \% \mathrm{CI}: 1.18-1.42)$ were significantly associated with depressive symptoms during the lockdown (see table 6).

Table 6: Binary logistic regression model for variables associated with depression $(n=1,810)$

\begin{tabular}{|l|c|c|c|}
\hline & \multicolumn{4}{|c|}{ Depression (PHQ-9) } \\
\hline Variable & OR & CI 95\% & $p$-value \\
\hline Gender, Male & 1.72 & $1.30-2.27$ & $.000^{* * *}$ \\
\hline Age & 0.98 & $0.97-0.99$ & $.000^{* * * *}$ \\
\hline HRGC individual & 1.47 & $1.13-1.90$ & $.004^{* *}$ \\
\hline Loneliness & 1.31 & $1.27-1.35$ & $.000^{* * *}$ \\
\hline Concerns about own health & 1.14 & $1.04-1.24$ & $.004^{* *}$ \\
\hline Stress due to social distancing during lockdown & 1.29 & $1.18-1.42$ & $.000^{* * *}$ \\
\hline
\end{tabular}

Note: Negelkerkes $\mathrm{R}^{2}: 0.403$. Note: ${ }^{* *} p<.01 ; * * p<.001$

Mediation analysis using PROCESS macro for SPSS 25 (IBM corp., Armonk, USA) was run to explore variables mediating the effect of being a HRGC individual on depression.

First, simple mediator models were run to test whether the effect of being a HRGC individual (X) on depression (Y) was mediated by concerns about own health (M) (model 1), by feelings of loneliness (M) (model 2), or by stress due to social distancing (M) (model 3). 
The results of the mediation analyses demonstrate that the indirect effects were only significant for concerns about own health (model 1: total effect: 1.49, 95\% CI: 1.005-1.978; direct effect: 1.067, 95\% CI:0.573-1.562; indirect effect: 0.42, 95\% CI: 0.2850.580; $\mathrm{p}=.000$ ) and feelings of loneliness as mediators (model 2: total effect: 1.50, 95\% CI: 0.999-2.007; direct effect: 0.68, 95\% CI: 0.290-1,079; indirect effect: 0.82, 95\% CI: 0.165-0.500; $\mathrm{p}=.000$ ), but not for stress due to social distancing.

Based on these simple mediator models, a serial multiple mediator model was run. Here, mediators are linked together in a causal chain, with one mediator $\left(\mathrm{M}_{1}\right.$ : concerns about own health) allowing to influence another mediator $\left(\mathrm{M}_{2}\right.$ : loneliness) (serial multiple mediator model: total effect: 1.48, 95\% CI: 0.978-1.99). As a result an indirect causal effect chain was observed, in which being part of the HRGC group increased concerns about own health, which in turn increased feelings of loneliness. Loneliness in turn affected depression (see figure 2).

\section{Discussion}

The proportion of individuals at increased risk for severe illness from Covid-19 (HRGC) in this study was 47\%. According to estimations of the RKI, $52 \%$ of all persons living in Germany aged 15 or older belong to a group at risk for severe illness from Covid-19 (Rommel et al., 2021 ). The primary aim of the current study was to investigate differences in mental health problems (such as depression, anxiety, psychosomatic symptoms and substance use) during the COVID-19 pandemic in HRGC individuals compared to LRCG individuals. We found that $35.9 \%$ of the HRGC individuals reported moderate depressive symptoms compared to $26.6 \%$ of the LRGC indivduals. The proportion of individuals with at least moderate depressive symptoms in the HRGC group is, hence, four times as high as in the German general population (Busch et al. 2013). According to Bäuerle et al. (2020) the rate of depression during the first lockdown in Germany was estimated at 14.3\% (PHQ-2 score $\geq 3$ ), while an Austrian study reported a rate of $26.5 \%$ for at least moderate depressive symptoms using a different questionnaire (Depression, Anxiety and Stress Scale - 21 items score 211) (Traunmüller et al. 2020). Moreover, $29.6 \%$ of the HRGC individuals exhibited clinically relevant symptoms of a generalized anxiety disorder while this applies to $21.4 \%$ of the LRGC individuals. Yet, the rate of generalized anxiety disorders in the German general population is only $5.9 \%$ (Hinz et al., 2017). Different studies confirm these increased rates of generalized anxiety disorders during the first period of the pandemic. A German study (Bäuerle et al. 2020) reported at least moderate symptoms of generalized anxiety disorders (GAD-7 score $\geq 10$ ) in $16.8 \%$ of the participants, while an Austrian study reported a rate of $21.3 \%$ (DASS-21 score of $\geq 7$ ) (Traunmüller et al. 2020). Compared to $9.3 \%$ in the German general population (Kocalevent et al., 2013), 15.6\% of the HRGC individuals and 7.6\% of the LRGC individuals showed clinically relevant somatic symptoms. $19.5 \%$ of the HRGC individuals and $9.7 \%$ of the LRGC individuals reported an elevated risk for suicide. Hence, the rate of an elevated risk for suicide is three times higher among HRGC individuals than in the German general population (Glaesmer et al. 2018).

The second aim of the current study was to investigate the impact of perceived loneliness, concerns about own health and stress due to lockdown measures on depressive symptoms. Using mediator models, we demonstrated that the direct effect of being an HRGC individual on depression was mediated by concerns about own health and feelings of loneliness. In a serial mediation model, an indirect causal effect chain was observed showing that being an HRCG individual increased concerns about own health, which increased feelings of loneliness and loneliness in turn affected depression. These findings show that HRGC individuals are more worried about their health during the pandemic than LRGC individuals and may therefore respond with social withdrawal to protect themselves and, consequently, experience higher levels of loneliness, which in turn has an impact on depressive symptoms.

The results clearly show that the mental health burden is higher among persons at increased risk of severe illness from Covid-19 compared to persons at low risk of severe illness from Covid-19. HRGC individuals are more concerned about the pandemic and experience higher levels of stress due to social isolation. Therefore, social support during lockdown periods is of utmost importance for individuals prone to psychological problems and for those who are concerned because of the pandemic. Consequently, people at increased risk of severe illness from Covid-19 should not only be protected from a Covid infection, but should be also provided psychosocial support (e.g. chat-based hotlines) in order to minimize negative consequences for their mental health during periods of lockdown.

This study has several limitations. Firstly, it needs to be pointed out that cross-sectional data were collected via an online survey tool, which was mainly promoted by German social service organisations. This recruitment process is likely to have caused a selection bias within the sample by primarily reaching individuals in need for advice from those organisations. Hence, the data collected is not representative of the German general population. Accordingly, representative cross-sectional samples and longitudinal data are desirable in future research. Secondly, the outcome instruments used in the survey were not entirely adapted to the time period of interest, i. e. the first lockdown in Germany. Therefore, it remains unclear whether the mental health burdens reported here changed due to the lockdown.

\section{Conclusions}


This study demonstrates that the mental health burden of the Covid-19 pandemic is high. This is especially true for individuals who are at increased risk of severe illness from Covid-19. These individuals have an increased need for psychosocial support during times of lockdown. These individuals, therefore, should be specifically supported by corresponding offers (e.g. by phone, in chats or online). Moreover, government officials should take into account the mental health consequences of measures aiming at social distancing. More research, however, is needed on possible long-term consequences of social distancing on mental health.

\section{Abbreviations}

$\begin{array}{ll}\text { COVID-19 } & \text { Coronavirus SARS-COV2 disease } 2019 \\ \text { SARS-CoV-2 } & \text { Severe acute respiratory syndrome coronavirus } 2 \\ \text { WHO } & \text { World Health Organization } \\ \text { RKI } & \text { Robert Koch Institut } \\ \text { HRGC } & \text { Individuals at increased risk of severe illness from Covid-19 } \\ \text { LRGC } & \text { Individuals at low risk of severe illness from Covid-19 } \\ \text { PHQ } & \text { Patient Health Questionnaire } \\ \text { GAD } & \text { Generalized Anxiety Disorder } \\ \text { SBQ-R } & \text { Suicide Behaviours Questionnaire - Revised } \\ \text { OSSS-3 } & \text { Oslo Social Support Scale - 3 }\end{array}$

\section{References}

WHO (2019). Coronavirus disease 2019 (COVID-19) situation report-34. Geneva, Switzerland [ https://www.who.int/docs/defaultsource/coronaviruse/situationreports/20200223-sitrep-34-covid-19.pdfsfvrsn=44ff8fd3_2].

WHO (2020). WHO announces COVID-19 outbreak a pandemic 2020 [ http://www.euro.who.int/en/health-topics/health-emergencies/coronaviruscovid-19/news/news/2020/3/who-announces-covid-19-outbreak-a-pandemic].

Bundesministerium für Gesundheit (BMG). Coronavirus SARS-CoV-2: Chronik der bisherigen Maßnahmen. URL: https://www.bundesgesundheitsministerium.de/coronavirus/chronik-coronavirus.html [16.03.2021].

Robert-Koch Institut (2021a). Tabelle mit Nowcasting-Zahlen zur R-Schätzung. URL:

https://www.rki.de/DE/Content/InfAZ/N/Neuartiges_Coronavirus/Projekte_RKI/Nowcasting_Zahlen_csv.html [09.03.2021].

Johns Hopkins University (2021). COVID-19 Dashboard by the Center for Systems Science and Engineering (CSSE) at Johns Hopkins University (JHU). URL: https://gisanddata.maps.arcgis.com/apps/opsdashboard/index.html\#/bda7594740fd40299423467b48e9ecf6 [16.03.2021]

Robert-Koch Institut (2021b). Epidemiologischer Steckbrief zu SARS-CoV-2und COVID-19. URL: https://www.rki.de/DE/Content/InfAZ/N/Neuartiges_Coronavirus/Steckbrief.html;jsessionid=B555BAF75F6201541A60FFEEFDB4EEEB.internet102? $\mathrm{nn}=13490888$ [16.03.2021]

Jordan, R. E., Adab, P., \& Cheng, K. K. (2020). Covid-19: risk factors for severe disease and death. BMJ (Clinical research ed.), $368, \mathrm{~m} 1198$. https://doi.org/10.1136/bmj.m1198 
Gao, Y. D., Ding, M., Dong, X., Zhang, J. J., Kursat Azkur, A., Azkur, D., Gan, H., Sun, Y. L., Fu, W., Li, W., Liang, H. L., Cao, Y. Y., Yan, Q., Cao, C., Gao, H. Y., Brüggen, M. C., van de Veen, W., Sokolowska, M., Akdis, M., \& Akdis, C. A. (2021). Risk factors for severe and critically ill COVID-19 patients: A review. Allergy, 76(2), 428-455. https://doi.org/10.1111/all.14657

Salari, N., Hosseinian-Far, A., Jalali, R., Vaisi-Raygani, A., Rasoulpoor, S., Mohammadi, M., Rasoulpoor, S., \& Khaledi-Paveh, B. (2020). Prevalence of stress, anxiety, depression among the general population during the COVID-19 pandemic: a systematic review and meta-analysis. Globalization and health, 16(1), 57. https://doi.org/10.1186/s12992-020-00589-w

Loades, M. E., Chatburn, E., Higson-Sweeney, N., Reynolds, S., Shafran, R., Brigden, A., Linney, C., McManus, M. N., Borwick, C., \& Crawley, E. (2020). Rapid Systematic Review: The Impact of Social Isolation and Loneliness on the Mental Health of Children and Adolescents in the Context of COVID19. Journal of the American Academy of Child and Adolescent Psychiatry, 59(11), 1218-1239.e3. https://doi.org/10.1016/j.jaac.2020.05.009

Guessoum, S. B., Lachal, J., Radjack, R., Carretier, E., Minassian, S., Benoit, L., \& Moro, M. R. (2020). Adolescent psychiatric disorders during the COVID-19 pandemic and lockdown. Psychiatry research, 291, 113264. https://doi.org/10.1016/j.psychres.2020.113264

Bundesregierung (2020). Erweiterung der beschlossenen Leitlinien zur Beschränkung sozialer Kontakte. Besprechung der Bundeskanzlerin mit den Regierungschefinnen und Regierungschefs der Länder vom 22.03.2020. URL:

https://www.bundesregierung.de/breg-de/themen/coronavirus/besprechung-der-bundeskanzlerin-mit-den-regierungschefinnen-und-regierungschefsder-laender-vom-22-03-2020-1733248 [09.03.2021].

Cacioppo, J. T., Hawkley, L. C., Norman, G. J., \& Berntson, G. G. (2011). Social isolation. Annals of the New York Academy of Sciences, 1231(1), 1722.

Matthews, T., Danese, A., Wertz, J., Odgers, C. L. , Ambler, A., Moffitt, T. E., Arseneault, L. (2016). Social isolation, loneliness and depression in young adulthood: a behavioural genetic analysis. Soc Psychiatry Psychiatr Epidemiol, 51(3), 339-348.

Bäuerle, A., Teufel, M., Musche, V., Weismüller, B., Kohler, H., Hetkamp, M., Dörrie, N., Schweda, A., \& Skoda, E. M. (2020). Increased generalized anxiety, depression and distress during the COVID-19 pandemic: a cross-sectional study in Germany. Journal of public health (Oxford, England), 42(4), 672-678. https://doi.org/10.1093/pubmed/fdaa106

Gualano, M. R., Lo Moro, G., Voglino, G., Bert, F., \& Siliquini, R. (2020). Effects of Covid-19 Lockdown on Mental Health and Sleep Disturbances in Italy. International journal of environmental research and public health, 17(13), 4779. https://doi.org/10.3390/ijerph17134779

Horigian, V. E., Schmidt, R. D., Feaster, D. J. (2021). Loneliness, Mental Health, and Substance Use among US Young Adults during COVID-19. Journal of Psychoactive Drugs, 53(1), 1-9.

Cullen W, Gulati G, Kelly BD. Mental health in the COVID-19 pandemic. QJM. 2020;113(5):311-2. https://doi.org/10.1093/qjmed/hcaa110. 
Gräfe K, Zipfel S, Herzog W, Löwe B. Screening psychischer Störungen mit dem "Gesundheitsfragebogen für Patienten (PHQ-D)". Diagnostica (2004) 50(4):171-81. doi: 10.1026/0012-1924.50.4.171

Kroenke K, Spitzer RL, Williams JBW. The PHQ-9: validity of a brief depression severity measure. J Gen Intern Med. (2001) 16:606-13. doi: 10.1046/j.1525-1497.2001.016009606.x

Spitzer RL, Kroenke K, Williams JBW, Löwe B. A brief measure for assessing generalized anxiety disorder: The GAD-7. Arch Intern Med. (2006) 166:1092- 7. doi: 10.1001/archinte.166.10.1092

Löwe, B., Decker, O., Müller, S., Brähler, E., Schellberg, D., Herzog, W., \& Herzberg, P. Y. (2008). Validation and standardization of the Generalized Anxiety Disorder Screener (GAD-7) in the general population. Medical care, 46(3), 266-274. https://doi.org/10.1097/MLR.0b013e318160d093

Kocalevent RD, Hinz A, Brähler E. Standardization of a screening instrument (PHQ-15) for somatization syndromes in the general population. BMC Psychiatry. (2013) 13:91. doi: 10.1186/1471-244X-13-91

Glaesmer H, Kapusta ND, Teismann T, Wagner B, Hallensleben N, Spangenberg L, et al. Psychometrische Eigenschaften der deutschen Version des suicide behaviors questionnaire revised (SBQ-R). Psychother Psycho Med Psychol. (2018) 68:346-52. doi: 10.1055/s-0043-118335

Osman A, Bagge CL, Gutierrez PM, Konick LC, Kopper BA, Barrios FX. The suicidal behaviors questionnaire-revised (SBQ-R): validation with clinical and nonclinical samples. Assessment. (2001) 8:443-54. doi: 10.1177/107319110100800409

de Jong-Gierveld, J., \& van Tilburg, T. G. (1999). Manual of the Loneliness Scale. Methoden en technieken.

Kilpeläinen K, Aromaa A, the ECHIM project (Hrsg) (2008) Europe- an Health Indicators: Development and Initial Implementation. Final report of the ECHIM project. National Public Health Institute, Helsinki.

Kocalevent, RD., Berg, L., Beutel, M.E. et al. Social support in the general population: standardization of the Oslo social support scale (OSSS-3). BMC Psychol 6, 31 (2018). https://doi.org/10.1186/s40359-018-0249-9

Robert Koch Institut (2020). Epidemiologischer Steckbrief zu SARS-CoV-2 und COVID-19. URL:

https://www.rki.de/DE/Content/InfAZ/N/Neuartiges_Coronavirus/Steckbrief.html;jsessionid=C915BAA6301122643053EA2059614DC6.internet112? $\mathrm{nn}=13490888$ \#doc13776792bodyText15

Hayes, A. F., \& Rockwood, N. J. (2016). Regression-based statistical mediation and moderation analysis in clinical research: Observations, recommendations, and implementation. Behaviour Research and Therapy. http://dx.doi.org/10.1016/j.brat.2016.11.001.

Hayes, A. F. (2013). Introduction to mediation, moderation, and conditional process analysis: A regression-Based approach. New York, NY: The Guilford Press.

Rommel A, von der Lippe E, Treskova-Schwarzbach M, Scholz S (2021) Bevölkerung mit einem erhöhten Risiko für schwere COVID-19-Verläufe in Deutschland. Auswertungen der Studie GEDA 2019/2020-EHIS. Journal of Health Monitoring 6(S2): 2-15. DOI: 10.25646/7858.2

Page 10/13 
Busch, M., Maske, U., Ryl, L. et al. (2013). Prävalenz von depressiver Symptomatik und diagnostizierter Depression bei Erwachsenen in Deutschland. Bundesgesundheitsblatt. 56, 733-739. https://doi.org/10.1007/s00103-013-1688-3

Traunmüller, C., Stefitz, R., Gaisbachgrabner, K., \& Schwerdtfeger, A. (2020). Psychological correlates of COVID-19 pandemic in the Austrian population. BMC public health, 20(1), 1395. https://doi.org/10.1186/s12889-020-09489-5

Hinz A, Klein AM, Brähler E, Glaesmer H, Luck T, Riedel-Heller SG, et al. (2017). Psychometric evaluation of the generalized anxiety disorder screener GAD-7, based on a large German general population sample. J Affect Disord. 210:338-44. doi: 10.1016/j.jad.2016.12.012

Kocalevent, R. D., Hinz, A., \& Brähler, E. (2013). Standardization of a screening instrument (PHQ-15) for somatization syndromes in the general population. BMC psychiatry, 13, 91. https://doi.org/10.1186/1471-244X-13-91

Glaesmer H, Kapusta ND, Teismann T, Wagner B, Hallensleben N, Spangenberg L, et al. (2018). Psychometrische Eigenschaften der deutschen Version des suicide behaviors questionnaire revised (SBQ-R). Psychother Psycho Med Psychol. 68:346-52. doi: 10.1055/s-0043-118335

\section{Declarations}

\section{Availabilty of data and materials}

Data are available upon request from the corresponding author (E-mail: d.deimel@katho-nrw.de).

\section{Acknowledgements}

We would like to thank to all survey participants and our colleagues at the German Insitute for Addiction and Prevention Research for piloting the survey.

\section{Funding}

The study was realised through funds from Catholic University of Applied Science NRW, Germany.

Author information

Affiliations

German Institute for Addiction and Prevention Research, Catholic University of Applied Sciences of North Rhine-Westphalia, Konrad-Adenauer-Ufer 79-81, 50668 Cologne, Germany

Daniel Deimel, Thorsten Köhler, Janina Dyba, Niels Graf

Department of Social Work, Catholic University of Applied Sciences of North Rhine-Westphalia, Robert-Schumann-Str. 25, 52066 Aachen, Germany Christine Firk 


\section{Contributions}

DD: Conceptualization study design, questionnaire and study organization, data analysis, drafted the manuscript; TK: statistical consulting; JD and $\mathrm{NG}^{*}$ : data interpretation; finalization and translation of the article; CF*: data analysis, data interpretation. All authors critically revised and approved the final draft of the manuscript.

*Both authors have contributed equally to this work.

\section{Corresponding author}

Correspondence to Daniel Deimel (d.deimel@katho-nrw.de)

\section{Ethics declarations}

\section{Ethics approval and consent to participate}

The study was reviewed and approved by Ethics Committee of the Catholic University NRW, Department Aachen, approval nr. AZ 2020-I (25.05.2020). The minimum age for participation in the survey was set at 18 years, whereby on the basis of the German guidelines, parental consent was not required. All participants gave electronic informed consent for the participation. The authors assert that all procedures contributing to this work comply with the ethical standards of the relevant national and institutional committees on human experimentation and the Helsinki Declaration of 1975 , as revised in 2008 . Participation in the study was anonymous.

\section{Consent for publication}

Not applicable.

\section{Competing interests}

The authors declare that they have no competing interests nor conflicts of interests.

\section{Figures}

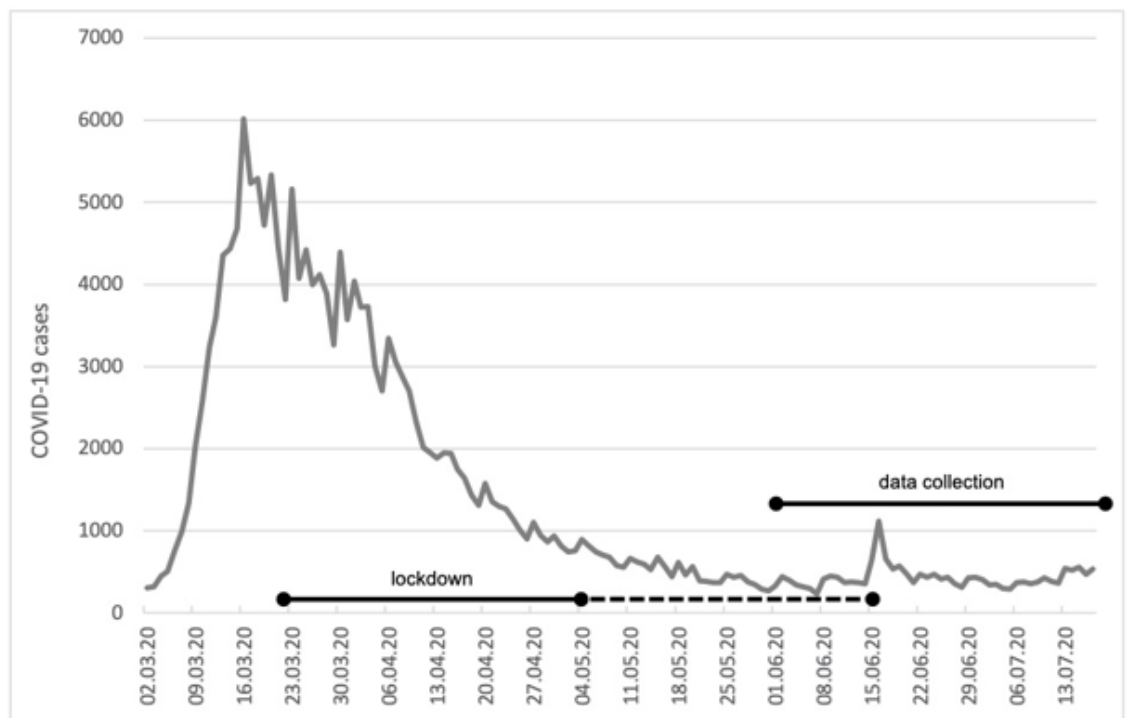


Figure 1

First Covid-19 lockdown in Germany. Sources: Own elaboration based on data from RKI, 2021a.

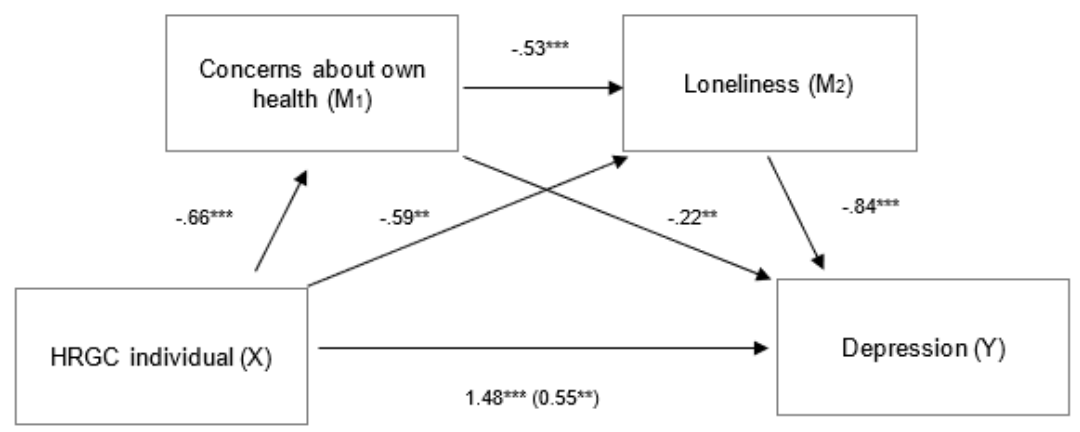

\section{Figure 2}

Serial multiple mediator model. Note: ${ }^{* \star} p<.01, * \star \star p<.001$ 